NASA/TM-2006-214402

(245)

Plasma Characteristics Measured in the Plume of a NEXT Multi-Thruster Array

John E. Foster, Michael Patterson, Eric Pencil, Heather McEwen, and Esther Diaz Glenn Research Center, Cleveland, Ohio 


\section{NASA STI Program . . . in Profile}

Since its founding, NASA has been dedicated to the advancement of aeronautics and space science. The NASA Scientific and Technical Information (STI) program plays a key part in helping NASA maintain this important role.

The NASA STI Program operates under the auspices of the Agency Chief Information Officer. It collects, organizes, provides for archiving, and disseminates NASA's STI. The NASA STI program provides access to the NASA Aeronautics and Space Database and its public interface, the NASA Technical Reports Server, thus providing one of the largest collections of aeronautical and space science STI in the world. Results are published in both non-NASA channels and by NASA in the NASA STI Report Series, which includes the following report types:

- TECHNICAL PUBLICATION. Reports of completed research or a major significant phase of research that present the results of NASA programs and include extensive data or theoretical analysis. Includes compilations of significant scientific and technical data and information deemed to be of continuing reference value. NASA counterpart of peer-reviewed formal professional papers but has less stringent limitations on manuscript length and extent of graphic presentations.

- TECHNICAL MEMORANDUM. Scientific and technical findings that are preliminary or of specialized interest, e.g., quick release reports, working papers, and bibliographies that contain minimal annotation. Does not contain extensive analysis.

- CONTRACTOR REPORT. Scientific and technical findings by NASA-sponsored contractors and grantees.
- CONFERENCE PUBLICATION. Collected papers from scientific and technical conferences, symposia, seminars, or other meetings sponsored or cosponsored by NASA.

- SPECIAL PUBLICATION. Scientific, technical, or historical information from NASA programs, projects, and missions, often concerned with subjects having substantial public interest.

- TECHNICAL TRANSLATION. Englishlanguage translations of foreign scientific and technical material pertinent to NASA's mission.

Specialized services also include creating custom thesauri, building customized databases, organizing and publishing research results.

For more information about the NASA STI program, see the following:

- Access the NASA STI program home page at http://www.sti.nasa.gov

- E-mail your question via the Internet to help@sti.nasa.gov

- Fax your question to the NASA STI Help Desk at 301-621-0134

- Telephone the NASA STI Help Desk at 301-621-0390

- Write to:

NASA STI Help Desk

NASA Center for AeroSpace Information 7121 Standard Drive Hanover, MD 21076-1320 
NASA/TM-2006-214402

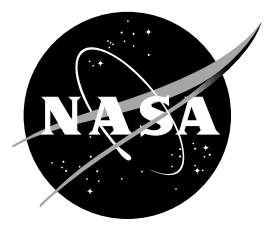

\section{Plasma Characteristics Measured in the Plume of a NEXT Multi-Thruster Array}

John E. Foster, Michael Patterson, Eric Pencil, Heather McEwen, and Esther Diaz Glenn Research Center, Cleveland, Ohio

Prepared for the

42nd Joint Propulsion Conference and Exhibit cosponsored by the AIAA, ASME, SAE, and ASEE

Sacramento, California, July 9-12, 2006

National Aeronautics and

Space Administration

Glenn Research Center

Cleveland, Ohio 44135 


\section{Acknowledgments}

The authors would like to acknowledge the tireless effort and assistance of Robert Roman and John Miller. Their combined efforts were key to a trouble-free test. The authors would also like to acknowledge Kevin McCormick and Bob Kohler who assisted in the fabrication of the array and diagnostics. Their efforts resulted in a fine piece of hardware.

This report is a preprint of a paper intended for presentation at a conference.

Because changes may be made before formal publication, this preprint is made available with the understanding that it will not be cited or reproduced without the permission of the author.

Level of Review: This material has been technically reviewed by technical management.

Available from

NASA Center for Aerospace Information 7121 Standard Drive

Hanover, MD 21076-1320
National Technical Information Service 5285 Port Royal Road Springfield, VA 22161 


\title{
Plasma Characteristics Measured in the Plume of a NEXT Multi-Thruster Array
}

\author{
John E. Foster, Michael Patterson, Eric Pencil, Heather McEwen, and Esther Diaz \\ National Aeronautics and Space Administration \\ Glenn Research Center \\ Cleveland, Ohio 44135
}

\begin{abstract}
Plasma properties in the plume produced by a " $3+1$ " NEXT thruster array operating at full power were mapped using a series of planar Langmuir probes. The Langmuir probes were swept across the diameters of each thruster as well as the centerline of the array at multiple downstream axial locations to produce a plasma "map" of the plume produced by the array. Such maps yielded the spatial distribution of the plasma density, the electron temperature and the plasma potential in the near field of the array. This spatial information provides insight into local plasma particle flow. Flow direction is particularly important from both an array lifetime and spacecraft-plume plasma interaction standpoint. The variation in the plume plasma parameters tended to vary in a manner consistent with both plume shape and overlap of adjacent plumes.
\end{abstract}

\section{Introduction}

To address lifetime and performance requirements for ion thruster missions requiring large propellant throughputs and high total impulse, a multi-thruster array can be utilized. In this case, a high performance ion thruster is integrated into an array of like thrusters such that lifetime and performance requirements of the system match the mission needs. A given engine's throughput requirement could be less than that which would be required if the thruster was operated alone-which translates into longer life. As an additional benefit, each engine could also be operated at full power for periods during the mission to reduce overall trip time. If the time at the full power operation is sufficiently small such that the wear accrued is less than that which would occur during reduced power operation for longer periods of time, then lifetime is also optimized. Such high power operation is possible particularly early on in the mission when the solar flux at the spacecraft is high (ref. 1).

Many multi-thruster array studies, both theoretical and experimental, have been carried out in the past to investigate these aforementioned positive attributes. Such investigations tested up to three thrusters featuring a host of electrostatic probes to carry out the investigation (refs. 2 to 9). These studies did not reveal any unexpected phenomena or potential barriers to the actual implementation of this approach.

A multi-thruster array consisting of four NASA's Evolutionary Xenon Ion Thrusters (NEXT) was tested at the NASA Glenn Vacuum Facility 6. As illustrated in figure 1, NEXT Engineering Model (EM) thrusters were arranged in a " $3+1$ " configuration where three thrusters were active and while a dormant thruster served as the spare. Here NEXT EM1, EM2, EM4, and EM5 were utilized in this test. This configuration is identical to the configuration designed for the Titan Orbiter mission (ref. 10). A detailed description of the thruster array may be found elsewhere (ref. 11). Of particular interest is the plasma particle and field distribution in the plume of an operating array of thrusters. The multi-thruster plume plasma determines the flow fields for charge exchange (CEX) ions as well as for charged sputter products. Both species effect thruster lifetime and performance. The backflow of charged species also affects the spacecraft itself particularly onboard scientific instruments. Backflowing CEX ions that find their way to the accelerator grid can give rise to erosion there. Sputtered components created local to the engine can also flow back to the thrusters, thereby giving rise to the formation of coatings or flakes. The charged, sputtered-material as well as the low energy CEX ions from the plume itself can backflow unto the spacecraft, potentially contaminating instruments or affecting the performance of electronics associated with the particular science mission. Depending on the potential of the spacecraft structures, the backflowing ions could also pose a sputter erosion threat as well. Finally, it should be pointed out that even if the incident energies of the charged specifies are sufficiently low, their collection on spacecraft surfaces will invariably affect the charge balance. It is conceivable that such charging could lead to arcing events and also affect the overall spacecraft potential.

In order to assess the plume induced plasma environment in the near field of the array, a series of electrostatic probe measurements were made in the plume of the multi-thruster array. The objective of the investigation was to map the plasma properties in the plume. These properties include plasma potential, electron temperature, and plasma 


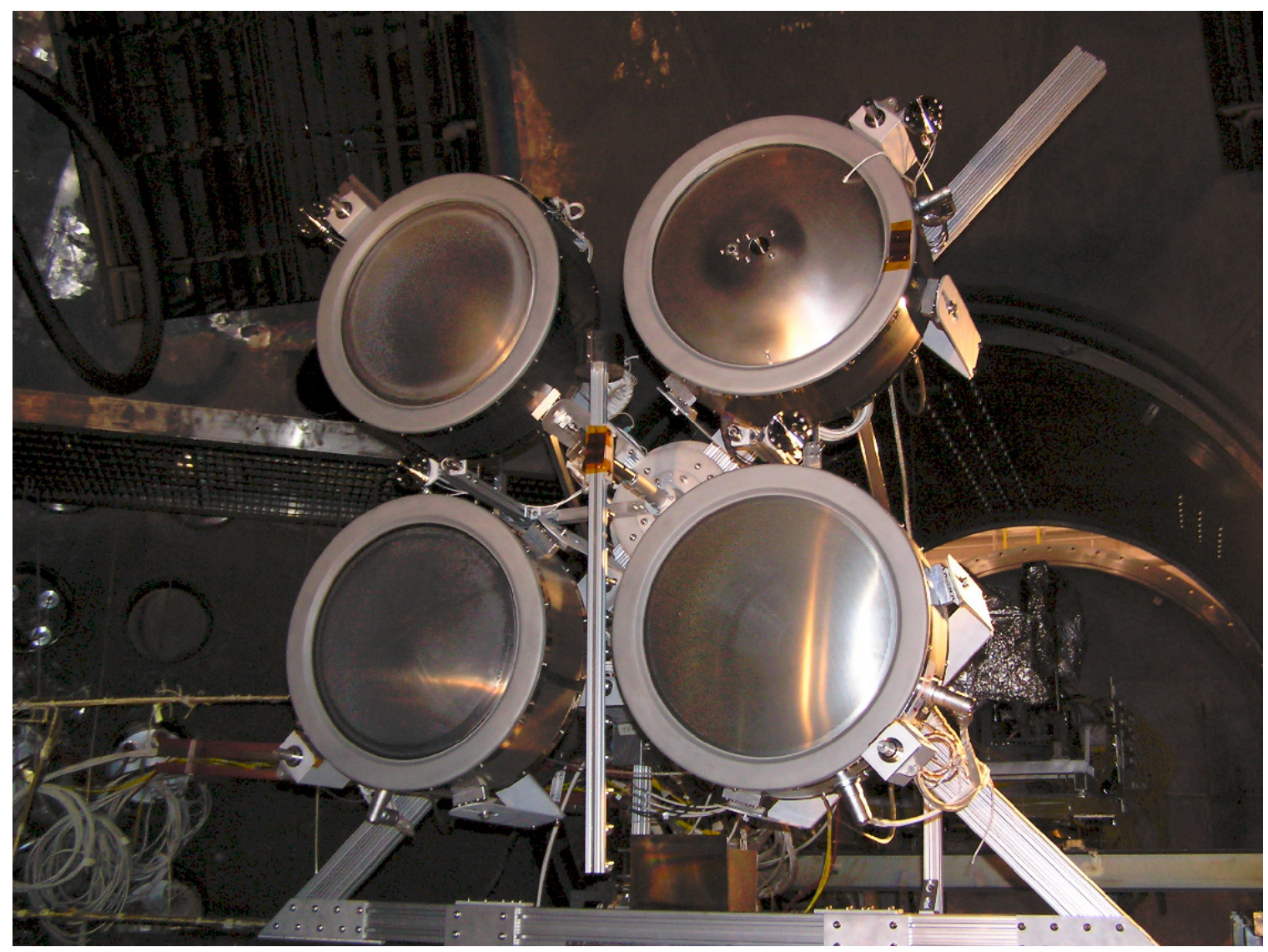

Figure 1.-The NEXT multi-thruster array in " $3+1$ " configuration installed in Vacuum Facility 6. Spare thruster can be seen in the upper right hand corner of the array.

density. These maps should yield much insight into the nature of the CEX flow field. Documented in this report are the results and analysis of this mapping survey which was performed with Langmuir probes in the plume produced by the NEXT " $3+1$ ” array.

\section{Approach}

The plume produced by the multi-thruster array was interrogated using Langmuir probes. The Langmuir probes were used to obtain plasma potential, electron temperature, and the plasma density. All measurements were made within a beam diameter $(\sim 40 \mathrm{~cm})$ to minimize the effect of facility-induced CEX ion contributions to the collected current.

The measured plasma parameters can be used to analyze the plume. In general, if the electron population in the plume is Maxwellian with temperature $T_{e}$, then the electron density, $n_{e}$, should follow the Boltzmann relation (ref. 12):

$$
n_{e}=n_{o} \cdot e^{\frac{e \phi}{k T_{e}}}
$$

Here, $n_{e}$ is the background plasma density, $k$ is Boltzmann's constant, $e$ is the elementary charge on the electron, and $\phi$ is the plasma potential. Following from equation (1), the spatial variations in the plume plasma density must be self-consistent with the variations in the local plasma potential, $\phi$. The spatial dependence of the electron temperature must also be accounted for. The spatial dependence of both parameters was obtained experimentally from the Langmuir probe I-V characteristics. These measurements were made at discrete locations in planes 


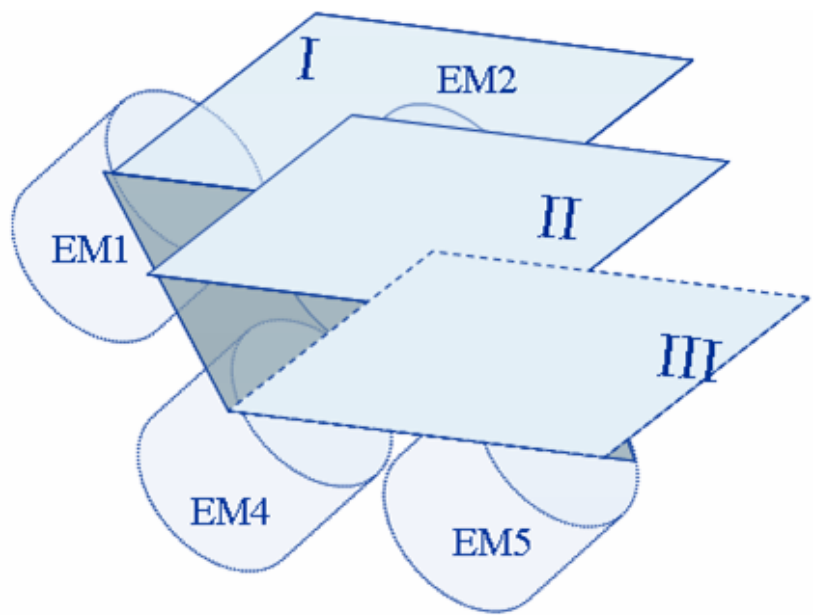

Figure 2(a).-Langmuir probe interrogation planes relative to the location of the 4 Engineering Model thrusters (EM) that make up the array.

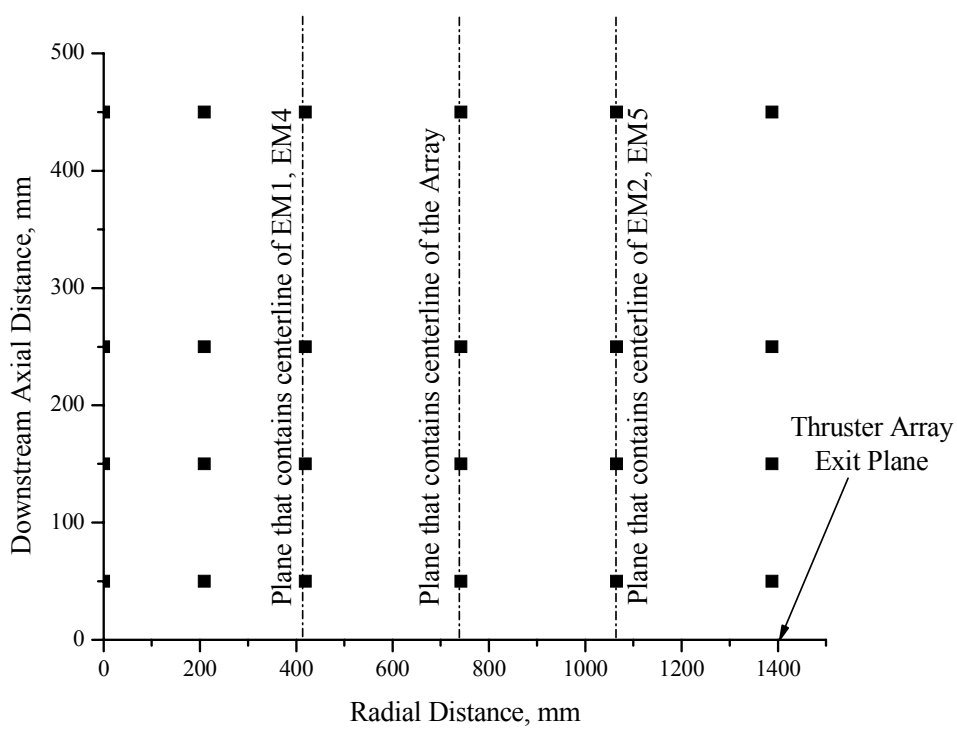

Figure 2(b).-Location of near-field plasma interrogation points in planes defined in figure 2(a).

downstream of the thruster array. The planes are designated with Roman numerals as indicated in figure 2(a). The actual location of each measurement made in a given plane is shown in figure 2(b). The number of discrete measurements that were made was limited so as to reduce "probe-in-plume" residence time. These measurements included interrogation points at the beam edge as well as at the array centerline. Provided the density gradients within the plume are not steep (a fact validated by measurements), the discrete mapping acquired should provide insight into the spatial variations within the intermixing plumes. Inputting this data into equation (1) allows one to determine a plume ion density shape function. This shape can be compared with actual measured values of the plasma density. 
In addition to gaining insight into the nature of the beam plasma's equilibrium state, it is also of interest to obtain some degree of insight into the relative contributions to the collected current due to CEX ions or beam ions. In general, the beam ion current contribution should follow the relation:

$$
j_{b}=e \cdot n_{b} \cdot \sqrt{\frac{2 e V_{b}}{m_{i}}}
$$

whereas, the CEX ion current follows the simple Bohm relation (ref. 12):

$$
j_{C E X}=0.61 \cdot e \cdot n_{C E X} \cdot \sqrt{\frac{k T_{e}}{m_{i}}}
$$

Here $m_{i}$ is the ion mass, $n_{b}$ is the beam density, and $n_{C E X}$ is the charge exchange ion density. In this regard, the current collected by a probe biased to ion saturation is convoluted with contributions from CEX ions as well as beam ions. This mixed nature makes extraction of the beam ion current density from total ion current difficult, particularly in facilities with elevated background pressure. The ratio of CEX ions to beam ions is expected to be a function of position. Clearly in the near field, at the outer edges of the beam (between thrusters for example) the ion current contribution can be expected to be largely due to ion flux from CEX ions. But further downstream, the measured ion current signal is a supposition of beam ions and CEX ions. In this regard, simple application of equation (2) or equation (3) at a particular location to obtain the ion density cannot be particularly accurate. However, provided the total average plasma density can be obtained from the electron saturation portion of the I-V curve, the CEX and beam ion contributions can be found by solving a system of equations:

$$
\begin{gathered}
n_{\text {total }}=n_{b}+n_{c e x} \\
j_{\text {tot }}=j_{b}+j_{c e x}
\end{gathered}
$$

Here, $n_{\text {total }}$ is the total plasma density and $j_{\text {tot }}$ is the total ion density. Here equation (5) is simply the sum of equations (2) and (3); therefore, equations (4) and (5) are functions of the beam ion density and the CEX ion density. The total ion current, described in equation (5) is determined experimentally from the ion saturation portion of the Langmuir probe I-V characteristic. The total plasma density can be estimated by determining the electron density from the electron saturation portion of the Langmuir I-V characteristic. The ratio of CEX ion density to beam ion density can therefore be calculated at all points where an I-V characteristic is made by solving this system of equations. This approach can be validated by direct comparison with plasma density measurements made on centerline of the array at very small axial displacements relative to the array itself. Here the plasma should be dominated by CEX ions.

The plasma potential profile will also allow for the determination of the degree neutrality via Poisson's equation. In this regard, based on the curvature in the potential, the difference in charge density can be obtained. For a completely neutralized ion beam, the curvature of the potential is zero. In a real system, this implies that the potential is either trivial within the beam or some constant value across the diameter of the beam. A linearly varying potential profile on centerline also satisfies the zero curvature condition. In this regard, the presence of non-zero potentials in and of themselves does not necessarily imply violations of quasi-neutrality. Small, nonlinear deviations in curvature across the beam, however, imply violations of quasi-neutrality. The variation in this parameter relative to the average plasma density as a function of radial position can yield much insight into the neutralization process, particularly under conditions where multiple thrusters are operating with a single neutralizer.

Plasma potential profiles will also yield insight into the flow direction of CEX ions and charged sputtered products. The radial and axial flow directions can be mapped by determining the plasma potential gradients. Because the plasma potential was made at various axial and radial locations, a rough map of the flow field can be computed. The flow field follows directly from the calculated electric field, $\vec{E}$ :

$$
\vec{E}=-\vec{\nabla} \phi
$$

Ions will flow in the direction of the electric field. The electric field can also be used to calculate the minimum energy that the ions could potentially impact the thruster array and spacecraft structures in the line of sight. The back 
flux on spacecraft structures can give rise to erosion if the incident energy is greater than the threshold sputter yield. Even if the flux does not sputter the array, deposition of engine related sputter products and xenon gas onto structures, particularly science instruments could pose a problem and thus must be quantified. Though such quantification is beyond the scope of the present effort, the measured potential distribution will be presented.

Presented in this report are data plots of plasma parameters acquired in the plume. These plots yield insight into the nature of the plume produced by the multi-thruster array. In this regard, the work described herein is a documentation of the plume plasma environment. The analysis described above will be applied to the data acquired and summarized in a future report. In this regard, the description of certain aspects of analysis that can be applied to this data serves to motivate the purpose of acquiring this data in the first place.

\section{Apparatus and Facility}

Multi-thruster array testing took place in the NASA GRC Vacuum Facility 6 (VF6) space simulation chamber. This vacuum facility measures $22.9 \mathrm{~m}$ long and $7.6 \mathrm{~m}$ in diameter. After the facility is roughed down using three mechanical pumps and four root blowers $\left(10^{-3}\right.$ Torr), the background pressure is reduced to base pressure through the operation of twelve cryopumps. On xenon, the pumping speed of the facility is approximately 400,000 1/s. Base pressure was approximately $1 \times 10^{-7}$ Torr, corrected for xenon. Taking the vacuum of space somewhat beyond earth to be approximately equal to that of the moon, then operating pressure levels that the array would actually experience in space is less than $1 \mathrm{nPa}$ or 10 pTorr (ref. 14). Clearly this is a "harder" vacuum environment than that which prevails in the test chamber. It follows then that the CEX production rate will necessarily be higher in the test facilities and thus the incident ion flux will also be significantly higher. Because the CEX current is proportional to the product of the ion beam density and the background neutral density, for a fixed ion beam current, the CEX flux should scale with the neutral densities (background pressure). The relevant neutral density in space (source of xenon neutrals for symmetric CEX) is the neutral flux that escapes the engine itself. The space background is mostly hydrogen and therefore CEX rates are therefore significantly reduced. The total CEX production rate in space is therefore due primarily to the ions interacting with neutral flux streaming from the thruster. This flux along with CEX production drops off at least as fast as $1 / \mathrm{r}^{2}$. This all implies that the bulk of the CEX production in space likely occurs in the near field of the thruster due to neutrals escaping the engine and neutralizer. Thus, in space, the local pressure in the near field determines the charge exchange flux. From this standpoint plasma measurements made in the near field should be more representative of the processes taking place in space. For a true comparison with space-like conditions, particularly further downstream, computation (or measurement in a "hard vacuum) of this neutral flow field is necessary.

Figure 3(a) shows a view of the multi-thruster array operating in VF6 with the primary diagnostic, the Faraday probe rake nearby. The array consisted of 3 active NEXT, engineering model ion thrusters along with an inactive engine that served as the array "flight spare." This arrangement constituted the so-called " $3+1$ " configuration. EM1 and EM5 featured $40 \mathrm{~cm}$ diameter ion optics, whereas EM4's optics were masked down to $36 \mathrm{~cm}$. EM2 served as a thruster spare and was not active during testing. EM2's ion extraction plane was terminated with a solid, dished stainless steel electrode that was fitted with plasma diagnostics consisting of a biasable accelerator electrode, a retarding potential analyzer, and a planar Langmuir probe. The array was operated at power levels ranging from $1.1 \mathrm{~kW}$ (one thruster active)to $20.4 \mathrm{~kW}$ ( 3 thrusters at full power, $6.8 \mathrm{~kW}$ each). Thruster operating conditions investigated may be found in table 1 . Additional details on the array and the array engineering demonstration test may be found in reference 11. As indicated in figure 2(a), the plasma measurements were made in 3 planes located downstream of the thrusters. As indicated in figure 3(a), a 6 element Faraday probe rake was used to interrogate the plume. The probes were translated relative to the multi-thruster array using a motion control system with submillimeter positioning accuracy. Only three of the six probes were used for the Langmuir probe measurements. These probes passed across the diameters of engineering model thrusters: EM1and EM2 (plane I), the center of the array (plane II), and the diameters of EM4 and EM5 (plane III). The three electrostatic probes on the Faraday probe rake used to interrogate the three planes of interest were planar in geometry whose normals were parallel with the axis of the thruster array. These molybdenum probes' collection areas were $1.13 \mathrm{~cm}$ in diameter. The active collection surface faced upstream (toward the thruster array). The side and back surfaces of the probe where shielded from plasma flux. 


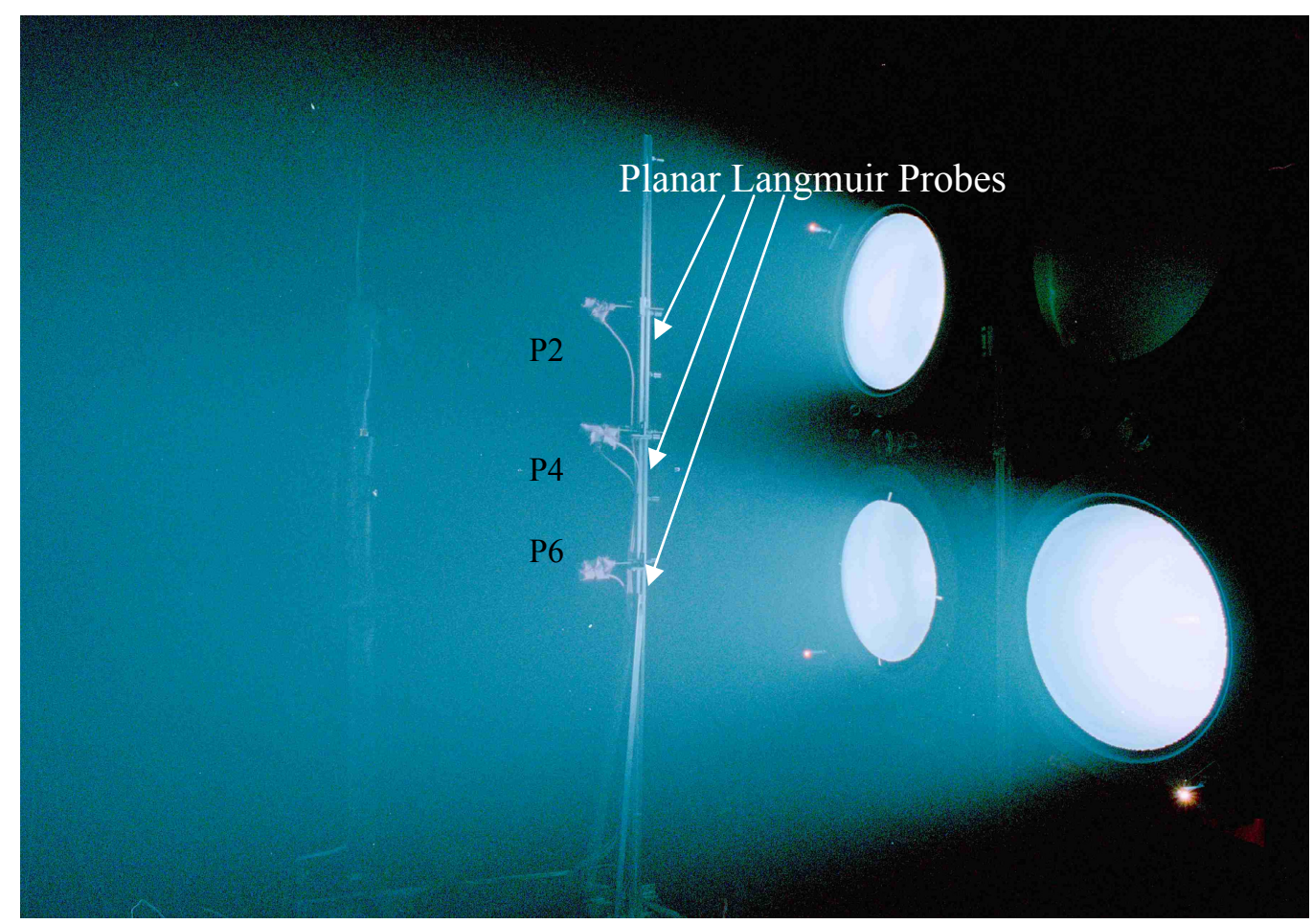

Figure 3(a).-Faraday probe rake interrogating plume of 3 active NEXT thrusters of a " $3+1$ " array arrangement. Note probes used for this investigation, each of which passes across thruster diameter and array centerline.

The probes were biased using a commercially available driver power supply. The acquisition and analysis of the probe's current-voltage characteristic was performed using software associated with this system. Simple thin sheath analysis was applied to the I-V characteristics acquired in the plume (ref. 15). This approach is justified because orbital effects affect the I-V characteristic of planar probes only when the sheath thickness approaches a significant fraction of the probe radius. Under these conditions, the probe collection surface is hemispherical. For the measurements made in this work the ratio of Debeye length to probe radius was less than $\sim 0.1$, thereby justifying this analysis approach. Electron temperature was determined from the electron retarding region of the characteristic. Plasma density was acquired from the electron saturation portion of the curved. In most cases the "knee" was well defined. Even so, because the "knee" occurs at the end of the exponentially increasing portion of the I-V characteristic, small uncertainties in the plasma potential can give rise to large uncertainties in the estimated electron saturation current. These uncertainties translate into electron density uncertainties of order 50 percent. Even so, the trends in the density as obtained using the electron saturation approach should systematically reflect actual trends in the variations in plasma density albeit with some uncertainty in the absolute magnitude. As mentioned earlier, the ion saturation current depends on both the CEX plasma density as well as the beam ion plasma density. Simple Bohm analysis of this current to obtain density is therefore inappropriate. A typical Langmuir probe I-V characteristic is shown in figure 3(b). The uncertainties in the plasma potential, electron temperature, and electron number density measurements were 15,25 , and 50 percent, respectively. 


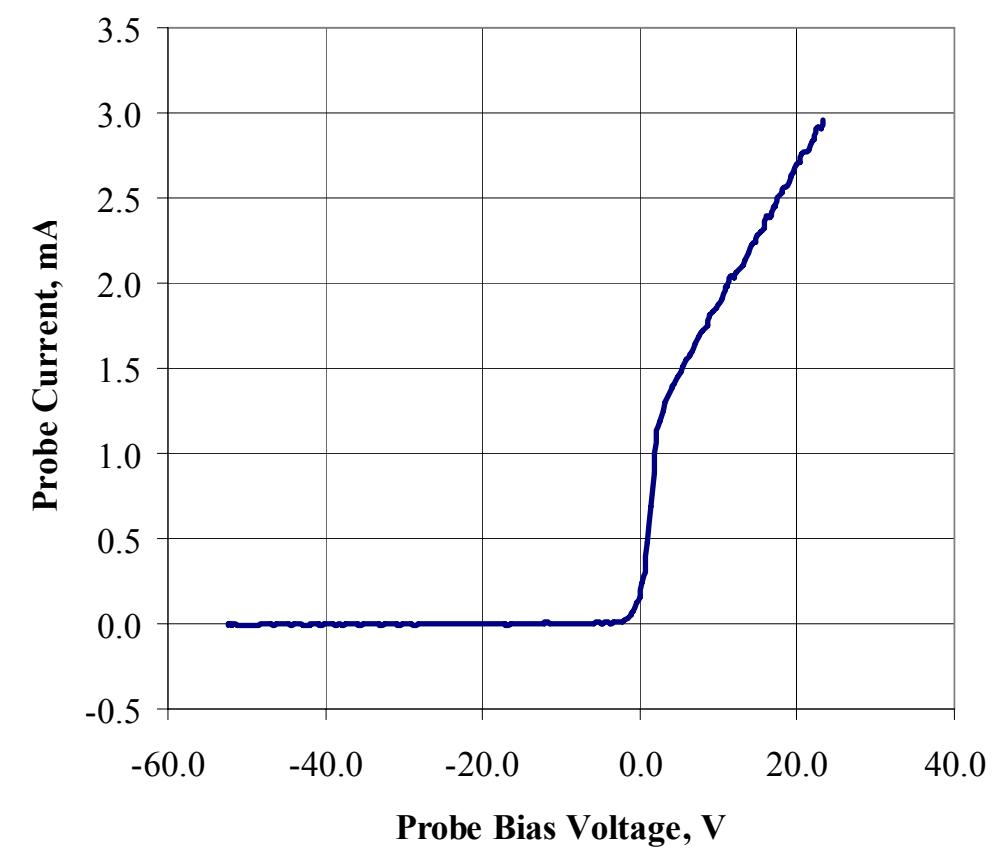

Figure 3(b).-Example of a typical Langmuir probe trace acquired in the plume produced by the multi-thruster array.

\section{Experimental Results}

The multi-thruster array was operated in a variety of configurations. The Langmuir probes interrogated the near field as defined as those axial downstream distances equal to or less than $450 \mathrm{~mm}$, just over a beam diameter. Detailed here are variations in the near field plume under conditions of 3 thrusters active at full power. A comprehensive review of all thruster configurations investigated including multiple engine operation with a single neutralizer may be found in reference 1. The thruster operating conditions for each of the thrusters active at full power are summarized in table I shown below.

TABLE 1.-INTERROGATED OPERATING CONDITION

\begin{tabular}{|c|c|c|c|c|c|c|c|}
\hline Configuration & Thruster & $\begin{array}{l}\text { Pressure, } \\
\text { torr }\end{array}$ & $\begin{array}{l}\text { Pin, } \\
\mathrm{kW}\end{array}$ & $\begin{array}{c}\text { Beam } \\
\text { voltage, } \\
\text { V }\end{array}$ & $\begin{array}{c}\text { Accelerator } \\
\text { voltage, } \\
\text { V }\end{array}$ & $\begin{array}{c}\text { Beam } \\
\text { current, } \\
\text { A }\end{array}$ & $\begin{array}{c}\text { Accelerator } \\
\text { current, } \\
\text { mA }\end{array}$ \\
\hline \multirow[t]{3}{*}{3 thrusters, full power } & EM1 & \multirow{3}{*}{$2.86 \times 10^{-6}$} & 6.88 & 1791 & -210 & 3.52 & 18.2 \\
\hline & EM4 & & 6.88 & 1789 & -209 & 3.52 & 18.9 \\
\hline & EM5 & & 6.88 & 1790 & -210 & 3.52 & 22.2 \\
\hline
\end{tabular}

As mentioned earlier, probes 2, 4, and 6 were operated as Langmuir probes to acquire plasma properties in the plume during array operation. Figure 2(b) indicates the points of interrogation. Axially, the closest measurements were made approximately $50 \mathrm{~mm}$ downstream of the multi-thruster array exit plane. From the data acquired in each interrogation plane (fig. 2(a)), a 2-D surface map was generated. Interpolation between points as displayed in the surface maps provides some insight into the magnitude and spatial behavior of the various plasma properties measured. These properties include electron temperature, plasma potential, and electron number density. Data associated with each plot is listed in the appendix of this paper.

\section{A. Plasma Potential}

Plasma properties in the plume were acquired in the three planes described in figure 2(a) using the planar Langmuir probes. Discussed in this section are plasma potential variations acquired in the near field of three thrusters operating at full power. In all cases, plasma potential was less than $4 \mathrm{~V}$ in the plume which was consistent with the measured energy of ions incident on the array as measured using retarding potential analyzers 


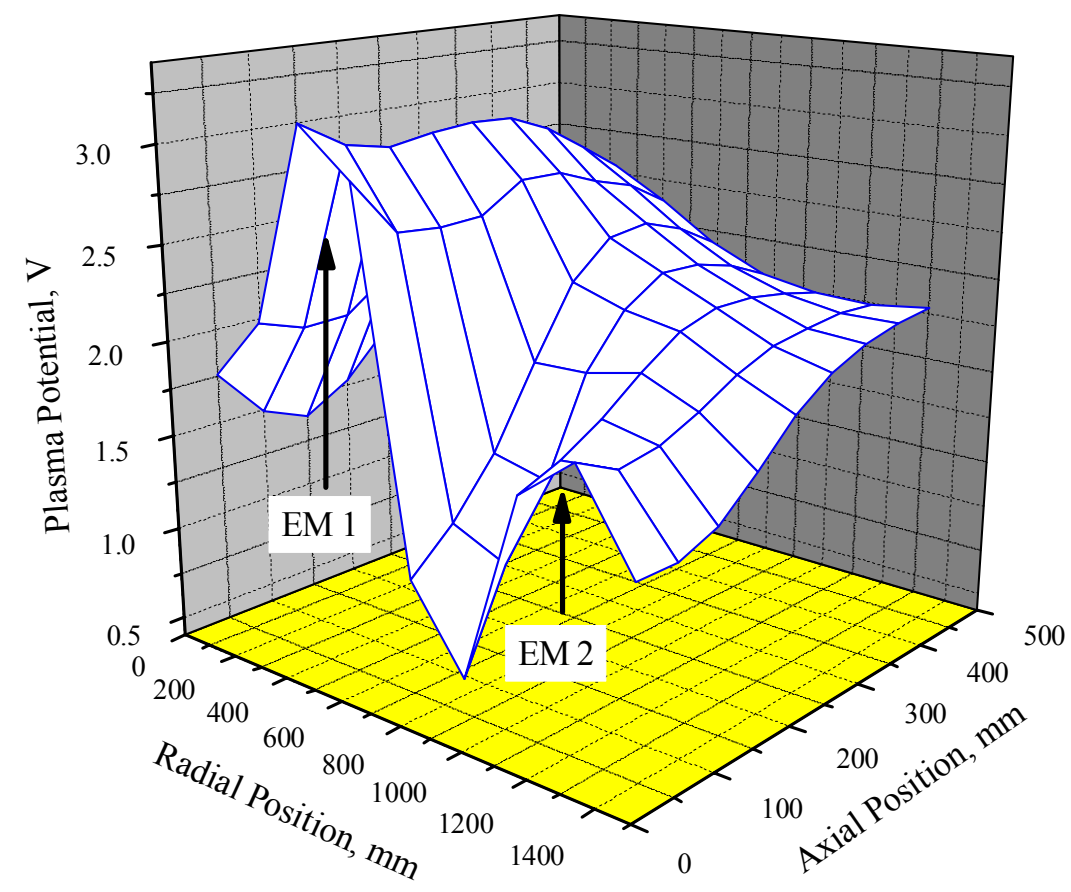

Figure 4(a).-Variation in plasma potential profile downstream of EM1 and EM2 (plane I) for three thrusters active at full power.

(ref. 17). The active thrusters included EM1, EM4, and EM5. Figure 4(a) illustrates the behavior of the plasma potential downstream of the array in plane I, which contains the diameters of EM1 and EM2. The observer vantage point illustrated in the figure is associated with a view looking downstream. Apparent in the figure are the two prominent but asymmetrical peaks just downstream of EM1 and EM2. The peaks are located near the centerlines of these two thrusters. The peak at the active thruster is approximately 1.7 times the magnitude at EM2. The peak in plasma potential on axis reflects the ion density profile. The peaked potential profile across the beam potential tends to confine neutralizing electrons. In a general sense, the plasma potential downstream of EM1 is highest at the closest axial position, near $\sim 3 \mathrm{~V}$, and decreases slowly with increasing axial distance to $\sim 2.5 \mathrm{~V}$ in the near field. The potential structure downstream of the dormant thruster is more complicated. In the very near field, the plasma detected in this region is due primarily to diffusion. Even so, in the plane of closest axial distance, its structure is similar to that of the active thruster. The peak is likely due to supposition of CEX plasma sources associated with the simultaneous operation of EM1, EM4, and EM5. EM2's centerline is approximately equidistant from the centerlines of the active thrusters, so by supposition, the maximum should occur near EM2's centerline. From geometric arguments, the local maximum plasma potential at EM2 can be explained. The plasma density contribution at EM2 due to contributions from EM 1, EM4, and EM5 should have its maximum value on centerline of EM2. After all, the shortest distance between the centerline of each active thrust and EM2 is the line connecting their respective centers. The similarity in profile at EM2 ends however with increasing axial distance. With increasing axial distance, the plasma potential actually increases nearly $0.5 \mathrm{~V}$, nearly approaching the magnitude of plasma potential at the same axial location downstream of EM1. In this case, along EM2's axis, downstream CEX ions would tend to flow toward the dormant thruster under the influence of the potential gradient, impacting it with energies of order $2 \mathrm{eV}$. Between the centerline of the two thrusters, the plasma potential exhibited a local minimum near ground potential at the closest axial position measured. The potential along a line parallel with the array axis but including the midpoint between EM1 and EM2 tended to increase with increasing axial distance increasing from $\sim 0.5 \mathrm{~V}$ at $\mathrm{Z}=50 \mathrm{~mm}$ to $2.2 \mathrm{~V}$ at $\mathrm{Z}=455 \mathrm{~mm}$. In the very near field of the array, the low plasma potentials measured between thrusters are attributed to lack of appreciable amounts of plasma there. In this case, the potential of the plasma would tend to approach the potential of ground potential surfaces in the vicinity. It should be pointed out that this trend of decreasing plasma potential as regions between thrusters or the dormant thruster is approached is quite general and independent of array configuration. Again these "zones" would tend to funnel low energy ions back to the array affecting the charge balance there. 


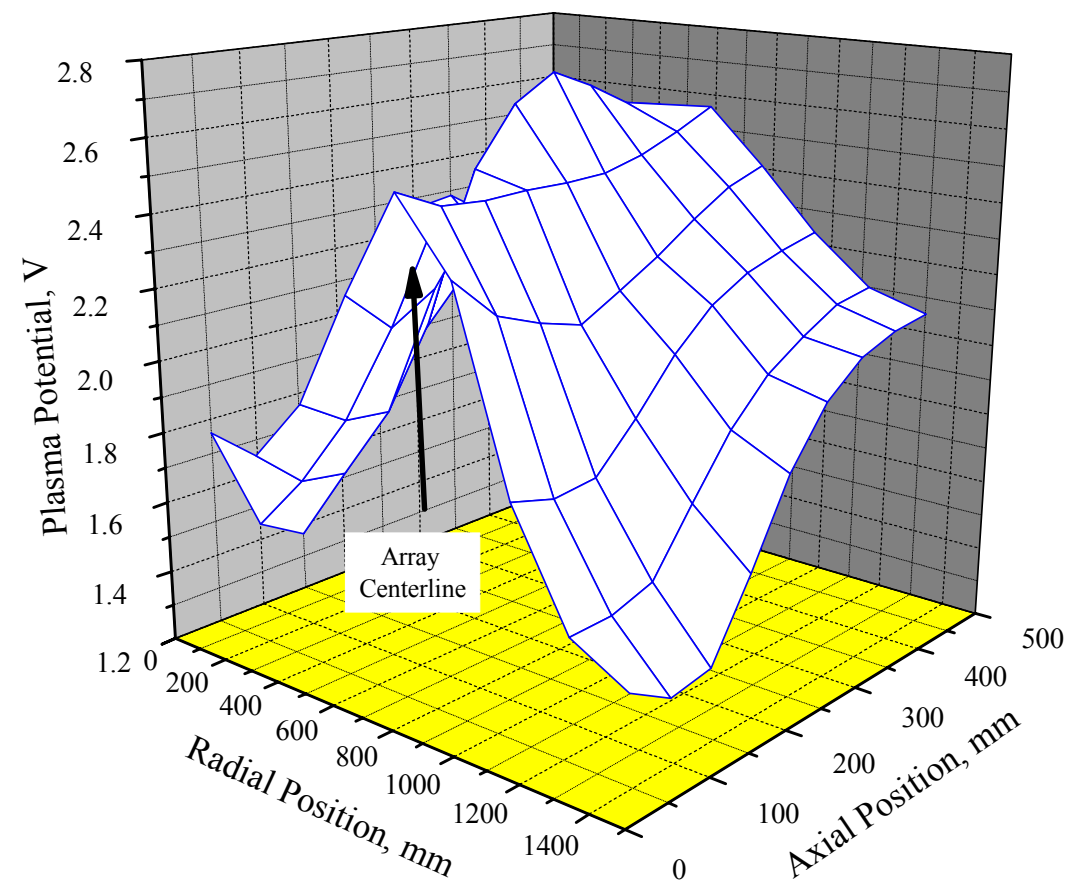

Figure 4(b).-Variation in plasma potential profile in midplane (plane II) of the array for three thrusters active at full power.

Plasma potential variations mapped in the plane that bisected the array (plane II) exhibited a prominent peak in the radial direction of the array, with the peak occurring on array centerline. This data is illustrated in figure 4(b). Because the array centerline is surrounded by three ion beams, this feature may in part be due to enhanced CEX production on array axis due to source terms in the beams of EM1, EM4, and EM5. The situation is akin to enhanced CEX production observed at the midpoint between three nearest neighbor beamlets of a set of ion optics. Axially, on centerline, the plasma potential is flat up to roughly $Z=250 \mathrm{~mm}$. Beyond $Z=250 \mathrm{~mm}$, the plasma potential rises to $\sim 2.8 \mathrm{~V}$ and then levels out somewhat with increasing axial distance. This structure in the near field has the potential to trap and funnel low energy ions toward the center of the array. This secondary rise in potential is likely due to plume overlap. This conjecture is consistent with Faraday probe measurements at $\mathrm{z}=250 \mathrm{~mm}$ which shows significant plume overlap at this distance and greater. Radially, away from the centerline, plasma potential as indicated drops off rapidly. In general, the radial profile is not symmetrical. This lack of symmetry is attributed to the presence of the dormant thruster which does not directly contribute to plasma production. In this case, the drop off in plasma potential radially, is more severe on the side of EM2, the dormant thruster. On the other hand, not only does the drop off with radial distance occur at a smaller rate in the direction toward $r=0$ (EM1 side), but there is also a local rise and subsequent flattening out of the plasma potential as $r=0$ is approached at axial positions $\mathrm{Z} 250 \mathrm{~mm}$ and greater (ref. 18). Both at $\mathrm{r}=0$ and $\mathrm{r}=1388 \mathrm{~mm}$, with increasing axial distance, the plasma potential also increases. This behavior is also attributed too beam expansion increasing axial distance. The absence of plasma potential peaks between thrusters EM1 and EM4 and EM2 and EM5, is likely due to the low plasma density in these regions, particularly close up. Overall, the potential structure on centerline must play some role in the electronplume dynamics. The measured potential structure would tend to sweep low energy electrons from those regions between thrusters and trap them on centerline. In this regard, the centerline potential structure may act as a reservoir of sorts, supporting neutralization.

The variations in plasma potential in plane III are illustrated in figure 4(c). Prominent in the figure are the local maxima along the centerlines of EM4 and EM5. The plasma potential on centerline of the thrusters drops off monotonically with increasing axial distance. The rate of the initial drop off is rapid but at distances greater than $Z=$ $200 \mathrm{~mm}$, the potential is practically flat. Beyond $\mathrm{Z}=200 \mathrm{~mm}$, the substantial overlap of the beam tends to flatten out plasma potential along a radial slice downstream. The drop off in plasma potential in the radial direction in the very near field is much more rapid. The rapid drop off is associated with the beam edge. Beyond the beam edge, plasma density drops off rapidly and thus the plasma potential approaches ground potential. At the midpoint, between the thrusters nearest the array exit plane, a local minimum in plasma potential $(\sim 1 \mathrm{~V})$ is observed. Again, plasma density 


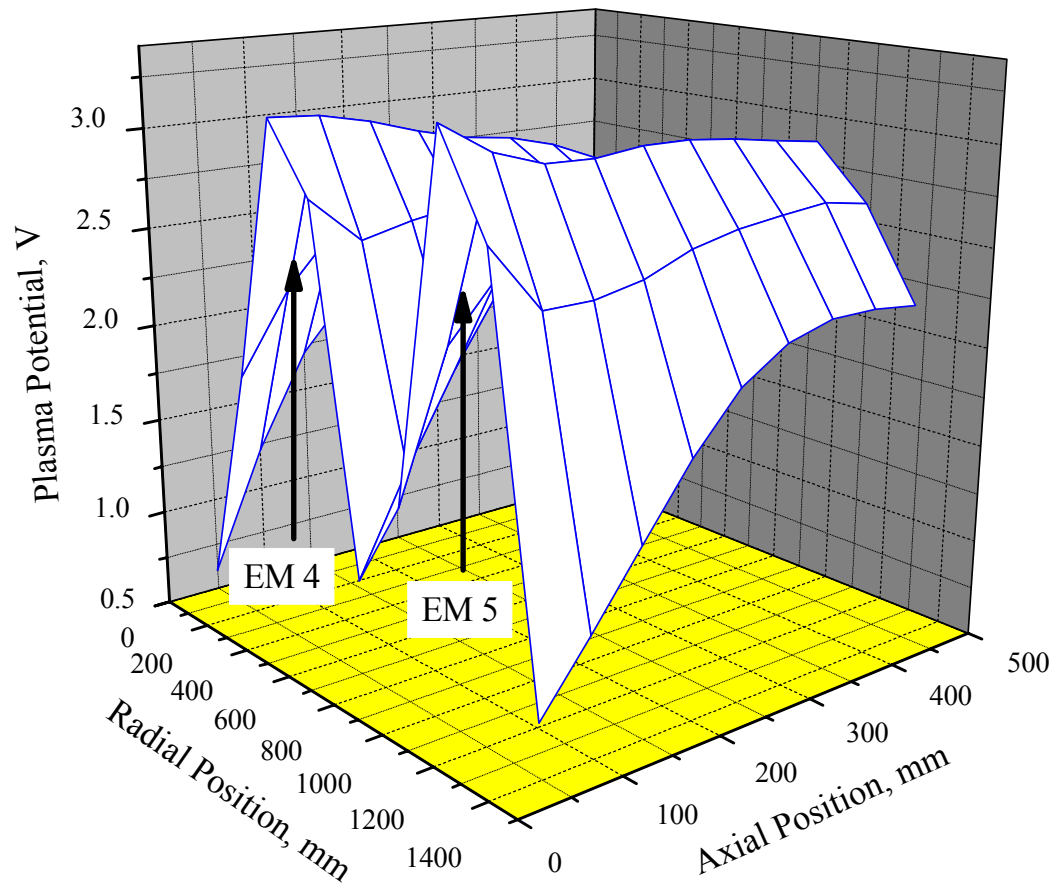

Figure 4(c).--Variation in the plasma potential profile in plane III, downstream of EM4 and EM5 for three thrusters active at full power.

is low here relative to the peaks in this parameter at EM4 and EM5. Here, the potentials close to ground are to be expected. With increasing axial distance, however, the plasma potential along this line actually increases only to flatten out around $2.5 \mathrm{~V}$ at approximately $\mathrm{Z}=250 \mathrm{~mm}$, a region where significant beam overlap occurs. The potential variations on axis in the near field would tend to funnel CEX ions that form between the array and $Z=$ $\sim 250 \mathrm{~mm}$ towards the array. The incident energies of such ions however would be small $\sim 3 \mathrm{~V}$. The flux however would change the charge dynamics of the overall spacecraft due to the very fact that the potential structure channels charge to the array.

\section{B. Electron Temperature}

The electron temperature in the plume determines in part the plasma potential structure inside the beam itself. Quasi-neutrality in the beam is maintained by the presence of beam neutralizing electrons. To keep electrons confined to the beam, the potential structure within the beam adjusts accordingly. Depending on array operating condition, the electron temperature can vary. Typically, this comes about due to the neutralizer operating at off-ideal conditions that gives rise to changes in the energy distribution of injected electrons. This distribution is selfconsistent with the potential profile. The potential structure must provide adequate electron containment to assure that the beam is neutralized; therefore, the electron energy distribution in part controls the nature of potential structures in the plume. It is the spatial distribution of potential structures in the beam in turn that determine the nature of ion flux incident on the thruster array or spacecraft structures. Indeed, as can be seen by direct comparison of plasma potential and electron temperature plots, electron temperature profiles appear as inverted reflections of the plasma potential profiles. Additionally, the probability of neutralizer electrons contributing to the background plasma density through ionization of the background increases with neutral density (pressure) and electron temperature. In this regard, mapping the electron temperature distribution can yield insight into the beam neutrality, the energy of back-flowing ions, and the production of background plasma. Electron temperatures measured in these surveys ranged between roughly 0.5 and $1 \mathrm{eV}$. 


\section{B. Electron Temperature}

The electron temperature in the plume determines in part the plasma potential structure inside the beam itself. Quasi-neutrality in the beam is maintained by the presence of beam neutralizing electrons. To keep electrons confined to the beam, the potential structure within the beam adjusts accordingly. Depending on array operating condition, the electron temperature can vary. Typically, this comes about due to the neutralizer operating at off-ideal conditions that gives rise to changes in the energy distribution of injected electrons. This distribution is selfconsistent with the potential profile. The potential structure must provide adequate electron containment to assure that the beam is neutralized; therefore, the electron energy distribution in part controls the nature of potential structures in the plume. It is the spatial distribution of potential structures in the beam in turn that determine the nature of ion flux incident on the thruster array or spacecraft structures. Indeed, as can be seen by direct comparison of plasma potential and electron temperature plots, electron temperature profiles appear as inverted reflections of the plasma potential profiles. Additionally, the probability of neutralizer electrons contributing to the background plasma density through ionization of the background increases with neutral density (pressure) and electron temperature. In this regard, mapping the electron temperature distribution can yield insight into the beam neutrality, the energy of back-flowing ions, and the production of background plasma. Electron temperatures measured in these surveys ranged between roughly 0.5 and $1 \mathrm{eV}$.

Figure 5(a) depicts changes in the electron temperature in the various planes of interrogation. Unlike the previous plots, the observer in this case is looking upstream toward the thruster array. The orientation change was done to highlight salient features present in the electron temperature surveys. Figure 5(a) illustrates the spatial distribution of the electron temperature as a function of position in plane I, which is just downstream of EM1 and the dormant thruster, EM2. As can be seen here, at the edges of the scan (which is outside the ion beam) and between thrusters, the electron temperature is highest. This is attributed to the fact that only those electrons energetic enough to escape the potential well within the ion beam can populate these regions. Analysis of the logarithm of the IV characteristic revealed linear functionality in the electron retarding region indicating a single temperature Maxwellian profile. Apparently, areas of higher electron temperature produced by hot electrons escaping the beam thermalize to produce a hotter, equilibrium distribution. In the near field, at a given axial location, local minima in

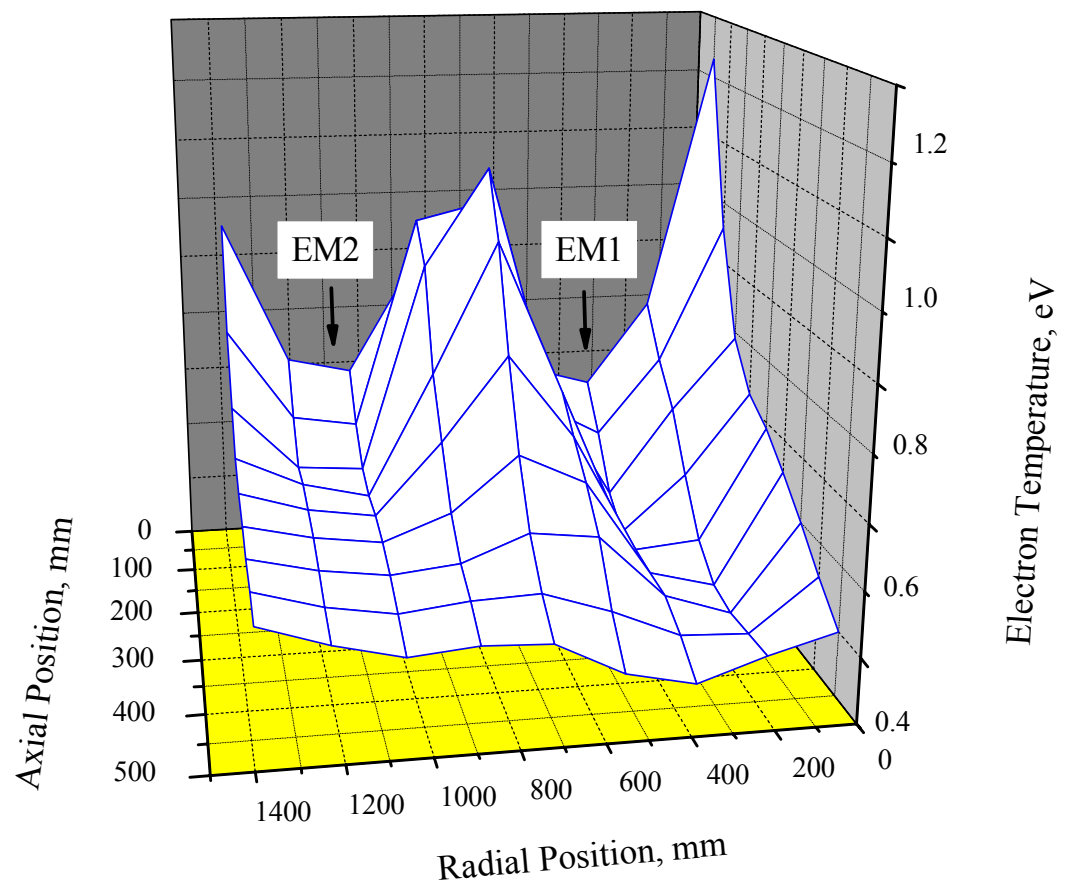

Figure 5(a).- Variation in the electron temperature profiles in plane I for three thrusters active at full power. 
the electron temperature were observed on centerline of thrusters EM1 and EM2. It is interesting to note that the local minimum even occurred at the dormant thruster. From the $Z=50 \mathrm{~mm}$ location outward to further downstream locations, the electron temperature decreased from $\sim 1 \mathrm{eV}$ to less than $0.5 \mathrm{eV}$. At distances greater than $\mathrm{Z}=350 \mathrm{~mm}$, the variation in electron temperature in the plane of interrogation was very small. In this respect, regions in plane I downstream of $Z=350 \mathrm{~mm}$ may be characterized as low temperature and isothermal. At these distances, the plumes from the three active thrusters are well mixed. It is likely that facility background pressure contributes to the flattening of the electron temperature profile.

It was mentioned that hotter electrons can escape the beam and populate the region between the beam. As discussed in the earlier section, potential gradients exist in the range of 2 to $4 \mathrm{~V}$ that tend to flush these hotter electrons downstream. This process has the effect of re-mixing the hotter electrons with the bulk population in the regions where the plume has overlapped. Careful analysis of the electron energy distribution function can confirm this notion. The measurement of this function however is difficult because facility background pressure can influence the shape of the electron energy distribution function, particularly in the area of interest- the tail.

Figure 5(b) illustrates the spatial distribution of the electron temperature along the array mid-plane (plane II). In this plane, the electron temperature is a local maximum between thrusters EM1 and EM4. This local maximum is consistent with "hotter" electrons escaping the potential well of the respective beams. Close to the exit plane, between thrusters, the plumes have not overlapped. Only beam neutralizing electrons with energies sufficiently large can diffuse into this region. The electron temperature decreases fairly rapidly in the near field along the paraxial line containing the midpoint between EM1 and EM4. The rapid drop off is attributed in part to potential gradients that exist along this line. Further downstream, the shallow potential well within the plume confines the cooler electrons while the more energetic ones escape and are dispersed throughout. A similar, but not as dramatic drop-off is observed along the paraxial line that contains the midpoint between EM2 and EM5. Here there is only 1 thruster active. In this regard, in the very near field, plasma properties are determined by diffusion of CEX plasma into this region as well as low level plasma production in the vicinity of the array. On centerline of the array the electron temperature is a local minimum that gradually decreases with increasing axial distance. The minimum on centerline in the near field is not unexpected. This location is farthest from the plume centers. Additionally, the electric field associated with the potential gradient which tends to sweep away electrons is also strongest here.

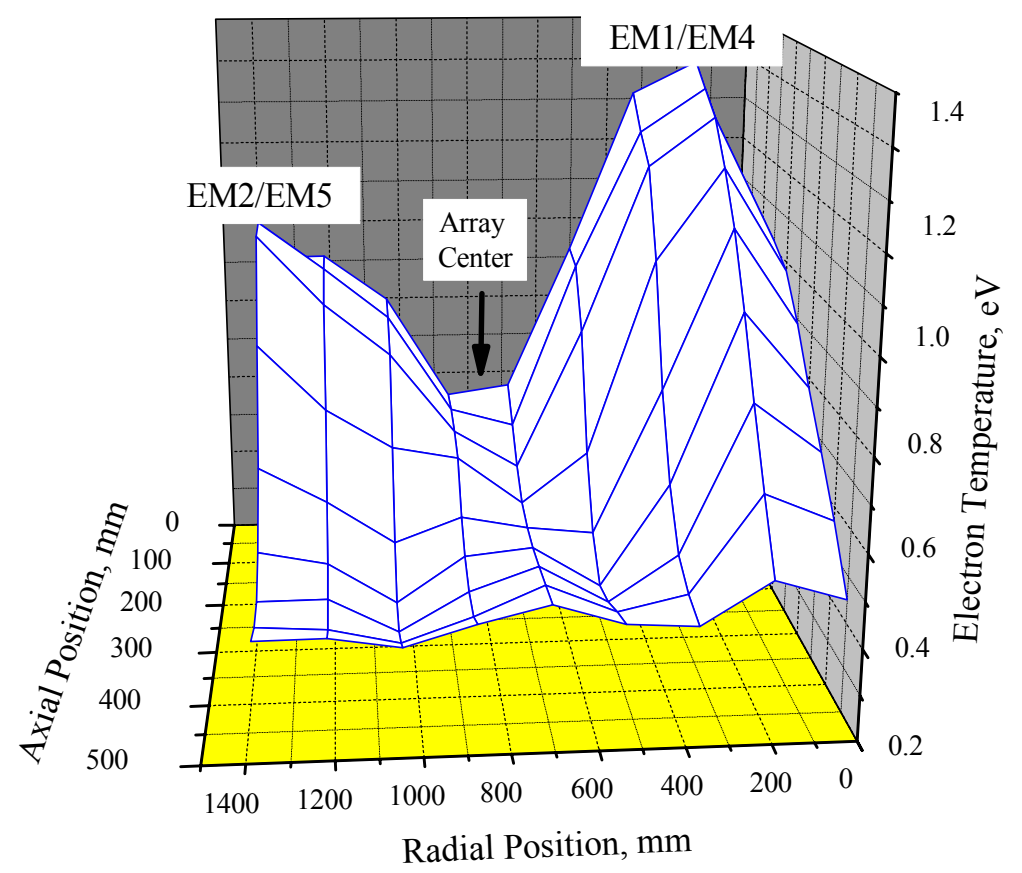

Figure 5(b).--Variation in the electron temperature profiles in plane II for three thrusters active at full power. 


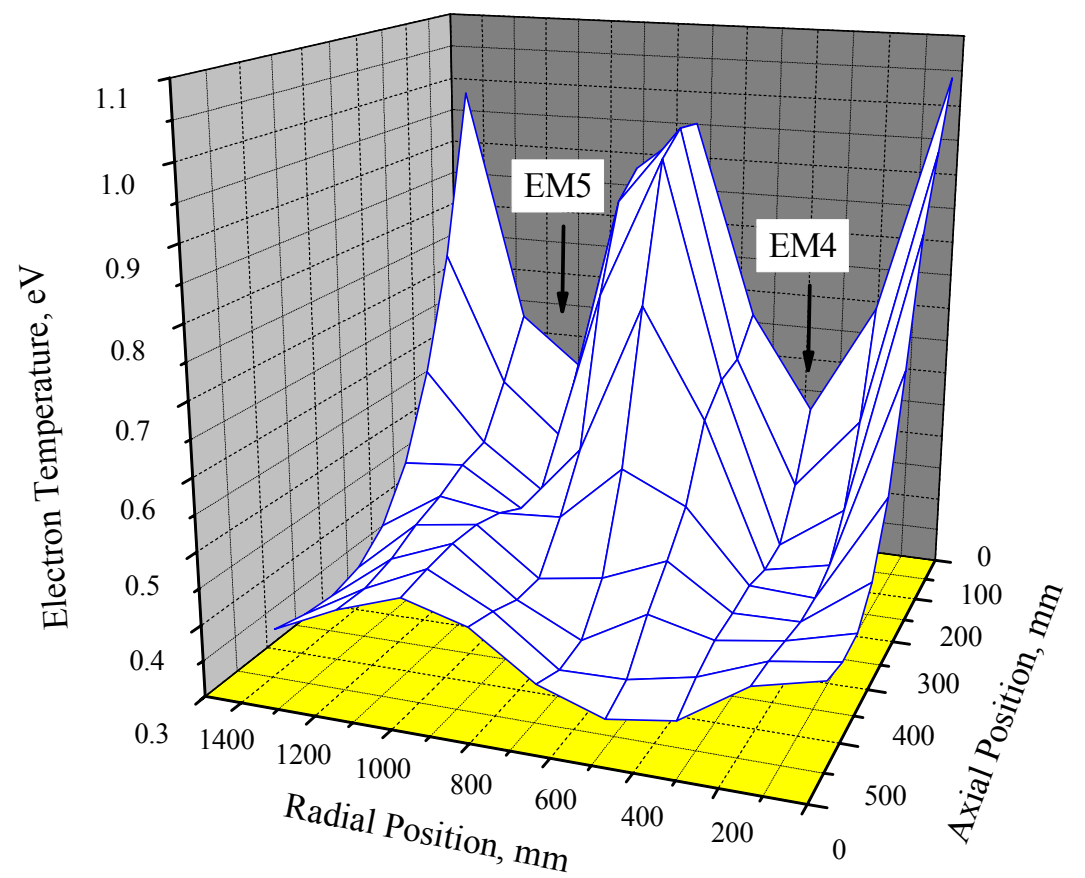

Figure 5(c).--Variation in the electron temperature profiles in plane III for three thrusters active at full power.

Figure 5(c) illustrates the electron temperature spatial distribution in plane III. Not surprisingly the profile is very similar to that observed in plane I (fig. 5(a)). Absent, however, is the asymmetry observed in figure 5(a). The absence of the asymmetry is due to the fact that both EM4 and EM5 are active. Here again the electron temperature decreases and eventually saturates at larger downstream axial distances. The peaks in electron temperature are again observed to occur in regions outside the beam and between thrusters. Indeed, the profiles look like an inverted version of the plasma potential plot.

\section{Electron Number Density}

As mentioned earlier, because the measured ion current is a collection of contributions from both CEX ions as well as beam ions, determining the plasma density from the ion saturation portion of the Langmuir I-V characteristic is problematic. Indeed, in regions between the beams, uncertainty in the plasma density as calculated using a Bohm or beam current model can be significant. These regions of dual ion populations occur between thrusters, on array centerline and at the plume boundaries. As such, the electron saturation current was used to calculate the electron number density. Under the assumption of quasi-neutrality in the beam, the electron number density equals the sum of the charge exchange number density and the ion beam number density. Though the uncertainty in the absolute magnitude of the plasma density is high ( $\sim 50$ percent $)$, from a systematic standpoint, the density determined from the electron saturation portion of the curve should at least yield the correct spatial trends. These measurements yielded densities that ranged between $10^{8} / \mathrm{cm}^{3}$ at the plume edges to just over $10^{10} / \mathrm{cm}^{3}$ on axis of an active thruster.

Electron density plots are also viewed from a vantage point similar to that presented for the electron temperature profiles. Figure 6(a) depicts the variations in the electron number density in plane I. Noticeable is the prominent peak on centerlines of thruster EM1. This density drops off with increasing axial distance. Radially, the drop off is much more rapid. In this regard, as expected, the density profile essentially follows the profile of the ion beam. The electron number density in the near field at the centerline of EM2 is nearly two orders of magnitude lower in comparison to the same location at EM1. Plasma density on axis and downstream of EM2 is largely due to diffusion and background plasma production. In this regard, the plasma density measured here is representative of the background plasma density. It is interesting to note that with increasing axial distance at least in the near field, the plasma density on centerline of EM2 actually increases. The increase downstream is largely due to plumes contributions from the active thrusters in intersecting the axis of EM2. Again this observation is consistent with significant measured plume overlap inferred from Faraday sweeps occurring at near field distances of order $250 \mathrm{~mm}$ 


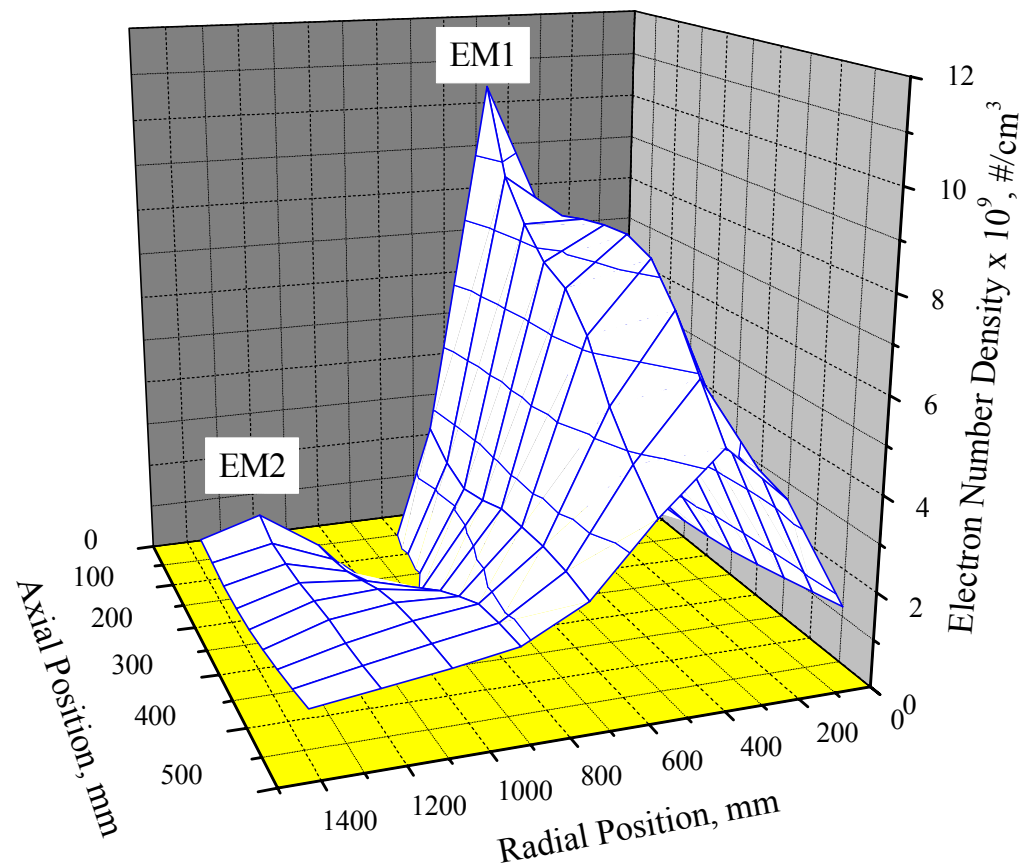

Figure 6(a).- Variation in the electron number density in the near field, plane I for three thrusters active at full power.

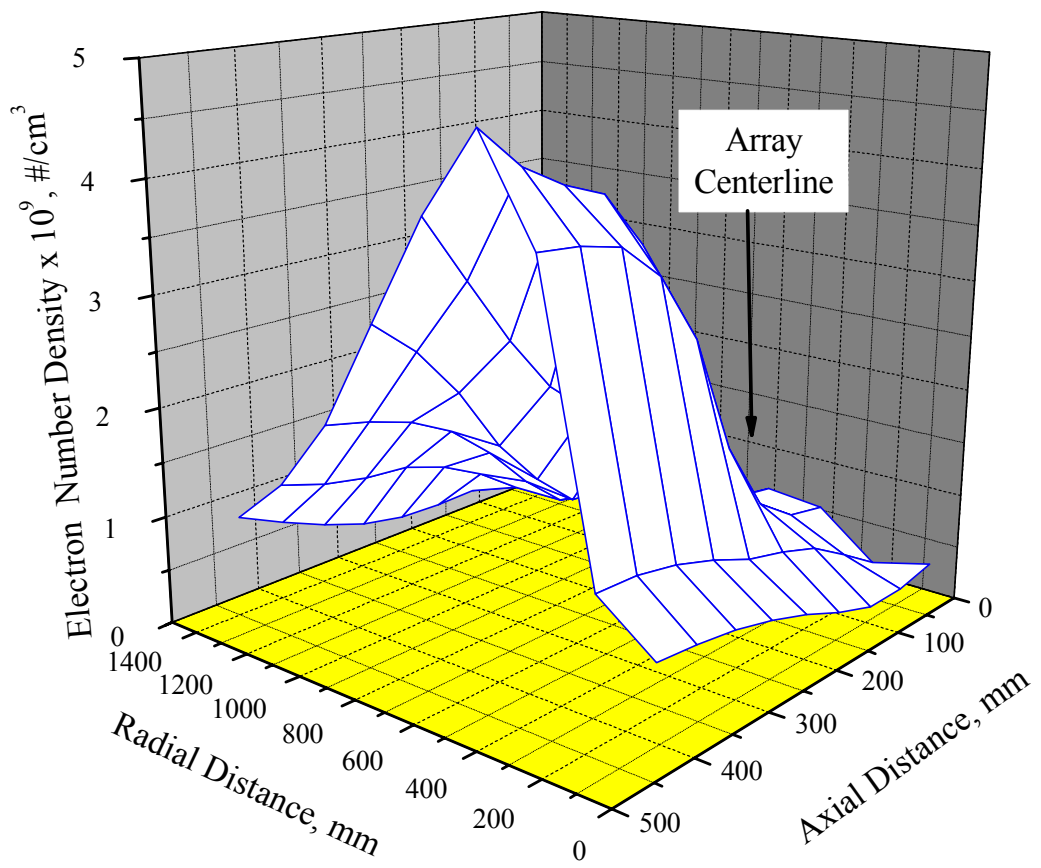

Figure 6(b).- -Variation in plasma density in the mid-plane (plane II) for three thrusters active at full power.

and beyond. Downstream of a paraxial line including the midpoint between EM1 and EM2, the plasma density also increases with increasing axial distance for similar reasons.

Figure 6(b) illustrates the spatial variations in the plasma density along the mid-plane of the array. Perhaps the most interesting attribute regarding the plot is the monotonic increase in electron density with increasing axial distance particularly on centerline. The increase in plasma density with axial distance is due to beam overlap 


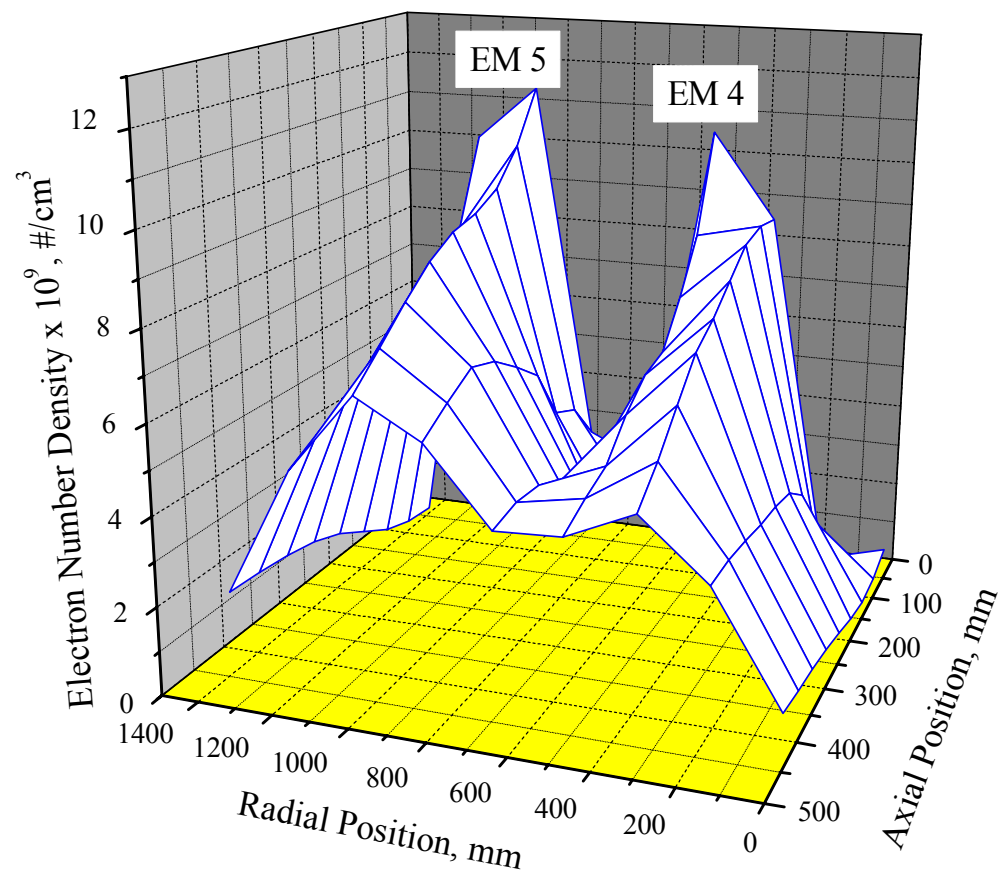

Figure 6(c).- -Variation in electron number density in plane III for three thrusters active at full power.

associated with finite plume divergence. With increasing axial distance the plumes eventually intersect the axis of the array, thus the density on array peaks downstream. The radial location of this peak is actually slightly offcenterline and skewed towards the line connecting the centers of EM1 and EM4. This skewing is expected since EM1 and EM4 are active while on the other side, only EM5 is active. Plume overlap and diffusion effects are stronger one the side with the two active thrusters. The downstream "bump" in potential discussed earlier is likely due to this on-centerline behavior of the plasma density. The increase in density with increasing axial distance occurs at radial positions far from array centerline as well due to finite divergence effect. In the radial direction, there is slight asymmetry in the overall profile due to the absence of a beam at EM2. It is expected that in the radial direction, this profile should flatten out with increasing axial distance, conforming to the mixed-beam profile.

Figure 6(c) illustrates the variations in the electron number density in plane III. Two prominent peaks are observed as expected at the centers of EM4 and EM5. Again, in the radial direction away form the centerline of each thruster, the density drops off rapidly, essentially following the beam profile. The rate of decrease in density magnitude with radial distance, however, does decrease with increasing axial distance. This behavior is due to plume expansion. Indeed, it is this effect that also gives rise to the slow increase in density along the paraxial line that bisects the distance between EM4 and EM5 with increasing axial distance as well. The cross sections of the plume profiles of EM4 and EM5 are slightly asymmetric. This asymmetry is due to thruster configuration differences in grid gaps between EM4 and EM5 and the reduced effective beam extraction area of EM4 (masked to $36 \mathrm{~cm}$ in diameter).

\section{Summary and Conclusions}

Plasma properties in the plume of a 3-NEXT thruster array operating at full power were mapped using a series of planar Langmuir probes. Variation in measured plasma potential, the electron temperature, and the plasma density tended to be consistent with plume shape and plume overlap. It was found that plasma potential as well as density tended to peak on centerline of the thrusters. On array centerline, however, the plasma density tended to be lowest in the near field and slowly rise with increasing axial distance. This increase with increasing axial distance is attributed to the finite divergence effect where plume expansion eventually intersects thruster array centerline. This variation in the near field gave rise to an axial potential profile which can drive the diffusion of CEX ions toward the thruster array. Because the potential variation was small $(<5 \mathrm{~V})$, the incident ion are expected to impact array structures at 
energies well below the sputter threshold of most metals. Such potential structures, however, should influence the overall charge balance of the array. This is of particular interest from a spacecraft charging standpoint. The measured electron temperature tended to be non-isothermal close to the exit plane but flattened out at further downstream conditions. Hotter electron populations were measured in regions between thrusters and at the beam edge. The electron temperature profiles tended to take the form of inverted versions of the plasma potential, confirming the self-consistency of these two parameters. 


\section{Appendix}

Listed in this section are tables (A1 to A3) containing the data presented in the two dimensional plasma maps discussed in the text. The data tables are presented according to interrogation plane. Each table contains the axial and radial location of the interrogation point as measured relative to the axial position of closest approach (50 mm downstream of the array). The center of array is located at position $r=742 \mathrm{~mm}$. Detailed locations of the thrusters in the array can be found in reference 11 .

TABLE A1.-PLASMA PROPERTIES IN PLANE I

\begin{tabular}{|c|c|c|c|c|}
\hline $\begin{array}{c}\text { Radial } \\
\text { position, } \\
\mathrm{mm}\end{array}$ & $\begin{array}{c}\text { Axial } \\
\text { position, } \\
\mathrm{mm}\end{array}$ & $\begin{array}{c}\text { Plasma } \\
\text { potential, } \\
\mathrm{V}\end{array}$ & $\begin{array}{c}\text { Electron } \\
\text { temperature, } \\
\mathrm{eV}\end{array}$ & $\begin{array}{c}\text { Electron number } \\
\text { density, } \\
\text { no. } / \mathrm{cm}^{3}\end{array}$ \\
\hline 0 & 50 & 1.8 & 1.13 & $3.36 \times 10^{8}$ \\
\hline 209 & 50 & 2.3 & 0.66 & $3.07 \times 10^{8}$ \\
\hline 419 & 50 & 3.4 & 0.56 & $1.08 \times 10^{10}$ \\
\hline 742 & 50 & 0.6 & 0.80 & $4.65 \times 10^{8}$ \\
\hline 1065 & 50 & 1.7 & 0.59 & $2.69 \times 10^{8}$ \\
\hline 1388 & 50 & 1.4 & 0.87 & $5.02 \times 10^{8}$ \\
\hline 0 & 150 & 1.4 & 0.69 & $4.11 \times 10^{8}$ \\
\hline 209 & 150 & 2.2 & 0.55 & $2.73 \times 10^{9}$ \\
\hline 419 & 150 & 3.0 & 0.43 & $9.25 \times 10^{9}$ \\
\hline 742 & 150 & 1.3 & 1.01 & $6.09 \times 10^{8}$ \\
\hline 1065 & 150 & 1.8 & 0.48 & $4.05 \times 10^{8}$ \\
\hline 1388 & 150 & 1.4 & 0.61 & $3.20 \times 10^{8}$ \\
\hline 0 & 250 & 1.8 & 0.59 & $5.75 \times 10^{8}$ \\
\hline 209 & 250 & 2.6 & 0.39 & $4.21 \times 10^{9}$ \\
\hline 419 & 250 & 3.0 & 0.46 & $8.62 \times 10^{9}$ \\
\hline 742 & 250 & 2.2 & 0.71 & $1.42 \times 10^{9}$ \\
\hline 1065 & 250 & 2.1 & 0.48 & $8.62 \times 10^{8}$ \\
\hline 1388 & 250 & 1.8 & 0.53 & $3.22 \times 10^{8}$ \\
\hline 0 & 450 & 2.1 & 0.40 & $1.21 \times 10^{9}$ \\
\hline 209 & 450 & 2.6 & 0.37 & $4.11 \times 10^{9}$ \\
\hline 419 & 450 & 2.6 & 0.33 & $4.54 \times 10^{9}$ \\
\hline 742 & 450 & 2.2 & 0.42 & $1.84 \times 10^{9}$ \\
\hline 1065 & 450 & 2.1 & 0.41 & $1.16 \times 10^{9}$ \\
\hline 1388 & 450 & 2.1 & 0.47 & $8.10 \times 10^{8}$ \\
\hline
\end{tabular}


TABLE A2.-PLASMA PROPERTIES IN PLANE II

\begin{tabular}{|c|c|c|c|c|}
\hline $\begin{array}{c}\text { Radial } \\
\text { position, } \\
\text { zmm }\end{array}$ & $\begin{array}{c}\text { Axial } \\
\text { position, } \\
\mathrm{mm}\end{array}$ & $\begin{array}{c}\text { Plasma } \\
\text { potential, } \\
\mathrm{V}\end{array}$ & $\begin{array}{c}\text { Electron } \\
\text { temperature, } \\
\mathrm{eV}\end{array}$ & $\begin{array}{c}\text { Electron number } \\
\text { density, } \\
\text { no./cm }\end{array}$ \\
\hline 0 & 50 & 1.8 & 0.84 & $4.89 \times 10^{8}$ \\
\hline 209 & 50 & 1.8 & 1.44 & $3.93 \times 10^{8}$ \\
\hline 419 & 50 & 2.0 & 1.19 & $8.52 \times 10^{8}$ \\
\hline 742 & 50 & 2.5 & 0.55 & $4.91 \times 10^{8}$ \\
\hline 1065 & 50 & 1.8 & 0.86 & $4.62 \times 10^{8}$ \\
\hline 1388 & 50 & 1.4 & 0.94 & $3.52 \times 10^{8}$ \\
\hline 0 & 150 & 1.4 & 1.02 & $4.12 \times 10^{8}$ \\
\hline 209 & 150 & 1.6 & 1.31 & $8.71 \times 10^{8}$ \\
\hline 419 & 150 & 2.0 & 1.07 & $1.21 \times 10^{9}$ \\
\hline 742 & 150 & 2.4 & 0.47 & $1.19 \times 10^{9}$ \\
\hline 1065 & 150 & 1.8 & 0.78 & $5.36 \times 10^{8}$ \\
\hline 1388 & 150 & 1.4 & 1.05 & $3.58 \times 10^{8}$ \\
\hline 0 & 250 & 2.1 & 0.89 & $6.79 \times 10^{8}$ \\
\hline 209 & 250 & 2.0 & 1.08 & $1.21 \times 10^{9}$ \\
\hline 419 & 250 & 2.6 & 0.55 & $3.50 \times 10^{9}$ \\
\hline 742 & 250 & 2.4 & 0.45 & $1.55 \times 10^{9}$ \\
\hline 1065 & 250 & 2.0 & 0.40 & $1.28 \times 10^{9}$ \\
\hline 1388 & 250 & 1.8 & 0.58 & $3.61 \times 10^{8}$ \\
\hline 0 & 450 & 2.1 & 0.45 & $9.75 \times 10^{8}$ \\
\hline 209 & 450 & 2.2 & 0.48 & $1.73 \times 10^{9}$ \\
\hline 419 & 450 & 2.5 & 0.39 & $4.58 \times 10^{9}$ \\
\hline 742 & 450 & 2.6 & 0.46 & $3.72 \times 10^{9}$ \\
\hline 1065 & 450 & 2.3 & 0.38 & $1.93 \times 10^{9}$ \\
\hline 1388 & 450 & 2.1 & 0.40 & $9.44 \times 10^{8}$ \\
\hline
\end{tabular}


TABLE A3.-PLASMA PROPERTIES IN PLANE III

\begin{tabular}{|c|c|c|c|c|}
\hline $\begin{array}{c}\text { Radial } \\
\text { position, } \\
\mathrm{mm}\end{array}$ & $\begin{array}{c}\text { Axial } \\
\text { position, } \\
\text { mm }\end{array}$ & $\begin{array}{c}\text { Plasma } \\
\text { potential, } \\
\mathrm{V} \\
\end{array}$ & $\begin{array}{c}\text { Electron } \\
\text { temperature, } \\
\mathrm{eV}\end{array}$ & $\begin{array}{c}\text { Electron number } \\
\text { density, } \\
\text { no. } / \mathrm{cm}^{3}\end{array}$ \\
\hline 0 & 50 & 0.6 & 1.05 & $7.35 \times 10^{8}$ \\
\hline 209 & 50 & 2.0 & 0.66 & $1.20 \times 10^{9}$ \\
\hline 419 & 50 & 3.3 & 0.56 & $1.17 \times 10$ \\
\hline 742 & 50 & 0.8 & 1.00 & $6.92 \times 10^{8}$ \\
\hline 1065 & 50 & 3.4 & 0.55 & $1.22 \times 10$ \\
\hline 1388 & 50 & 0.8 & 0.99 & $2.37 \times 10^{8}$ \\
\hline 0 & 150 & 1.7 & 0.86 & $4.08 \times 10^{8}$ \\
\hline 209 & 150 & 2.6 & 0.42 & $3.90 \times 10^{9}$ \\
\hline 419 & 150 & 3.0 & 0.44 & $9.43 \times 10^{9}$ \\
\hline 742 & 150 & 2.0 & 0.94 & $1.30 \times 10^{9}$ \\
\hline 1065 & 150 & 3.0 & 0.42 & $9.67 \times 10^{9}$ \\
\hline 1388 & 150 & 1.4 & 0.59 & $5.70 \times 10^{8}$ \\
\hline 0 & 250 & 2.1 & 0.54 & $7.43 \times 10^{8}$ \\
\hline 209 & 250 & 2.6 & 0.38 & $4.30 \times 10^{9}$ \\
\hline 419 & 250 & 2.9 & 0.42 & $7.80 \times 10^{9}$ \\
\hline 742 & 250 & 2.6 & 0.51 & $3.50 \times 10^{9}$ \\
\hline 1065 & 250 & 3.0 & 0.45 & $8.94 \times 10^{9}$ \\
\hline 1388 & 250 & 2.0 & 0.40 & $1.40 \times 10^{9}$ \\
\hline 0 & 450 & 2.1 & 0.42 & $1.25 \times 10^{9}$ \\
\hline 209 & 450 & 2.6 & 0.39 & $4.11 \times 10^{9}$ \\
\hline 419 & 450 & 2.6 & 0.32 & $4.76 \times 10^{9}$ \\
\hline 742 & 450 & 2.6 & 0.37 & $4.52 \times 10^{9}$ \\
\hline 1065 & 450 & 2.9 & 0.44 & $6.53 \times 10^{9}$ \\
\hline 1388 & 450 & 2.2 & 0.37 & $1.96 \times 10^{9}$ \\
\hline
\end{tabular}





\section{References}

1. Oh, D., "Evaluation of Solar Electric Propulsion Technologies for Discovery Class Missions," 41st AIAA JPC, Tucson, July 10-13, 2005.

2. Pawlik, E.V., "An experimental evaluation of array of three electron-bombardment ion thrusters," NASA TN D-2597, 1965.

3. Rawlin, V.K., and Mantenieks, M.A., "A multiple thruster array for 30-cm thrusters," AIAA Paper 75-402, 1975.

4. Lathem, W.C., "Particle and Field Measurements on Two J-Series 30 Centimenter Thrusters," NASA TM $81741,1981$.

5. Brophy, J.R., "Computer-controlled operation of a two engine xenon ion propulsion system," AIAA Paper 871007, 1987.

6. Roy, R.I.S., Hastings, D.E., and Gatsonis, N.A., "Ion-Thruster Plume Modeling for Backflow Contamination," Journal of Spacecraft and Rockets, Vol., 33, No. 4, 1996, 524.

7. Tierney, C.M., Brophy, J.R., and Mueller, J., "Plume Characteristics of a Multiple Ion Source Thruster,"AIAA Paper 95-3067, 1995.

8. Wang, J., Brophy, J., and Brinza, D., “A global analysis of ion thruster plume interactions for interplanetary spacecraft," AIAA Paper 97-3194, 1997.

9. Hargus, W.A. and Cappelli, M.A., "Interactions within a cluster of low power Hall thrusters," AIAA paper 2003-5006, 2003.

10. Oberto, R. et al., “Advanced Projects Design Team, Titan Orbiter 2003-10,” JPL Report ID \#658, 2003.

11. Patterson, M.J. et al., "NEXT Multi-Thruster Array Test-Engineering Demonstration," AIAA Paper Number 2006-5180, 2006; Also see "Multi-thruster Array Engineering Demonstration Test," NASA GRC Final Report, 2006.

12. Chen, F., Introduction to Plasma Physics and Controlled Fusion, New York, pp 8-10, 1984.

13. IBID, pp. 295-296.

14. http://www.reference.com/browse/wiki/Vacuum

15. Hershkowiz, N., "How Langmuir Probes Work", in Plasma Diagnostics, Vol 1. ed. By O. Auciello and D.L. Flamm(Academic Press, Boston, 1989).

16. Foster, J.E. et al, "Neutralizer Characterization of a NEXT Multi-Thruster Array with Electrostatic Probes," AIAA Paper 2006-5184.

17. McEwen, H. et al., "Characterization of Plasma Flux Incident on a Multi-Thruster Array," AIAA Paper 51832006, 2006.

18. Pencil, E. et al., "Ion Beam Characterization of a NEXT Multi-Thruster Array Plume," AIAA Paper 51822006, 2006. 


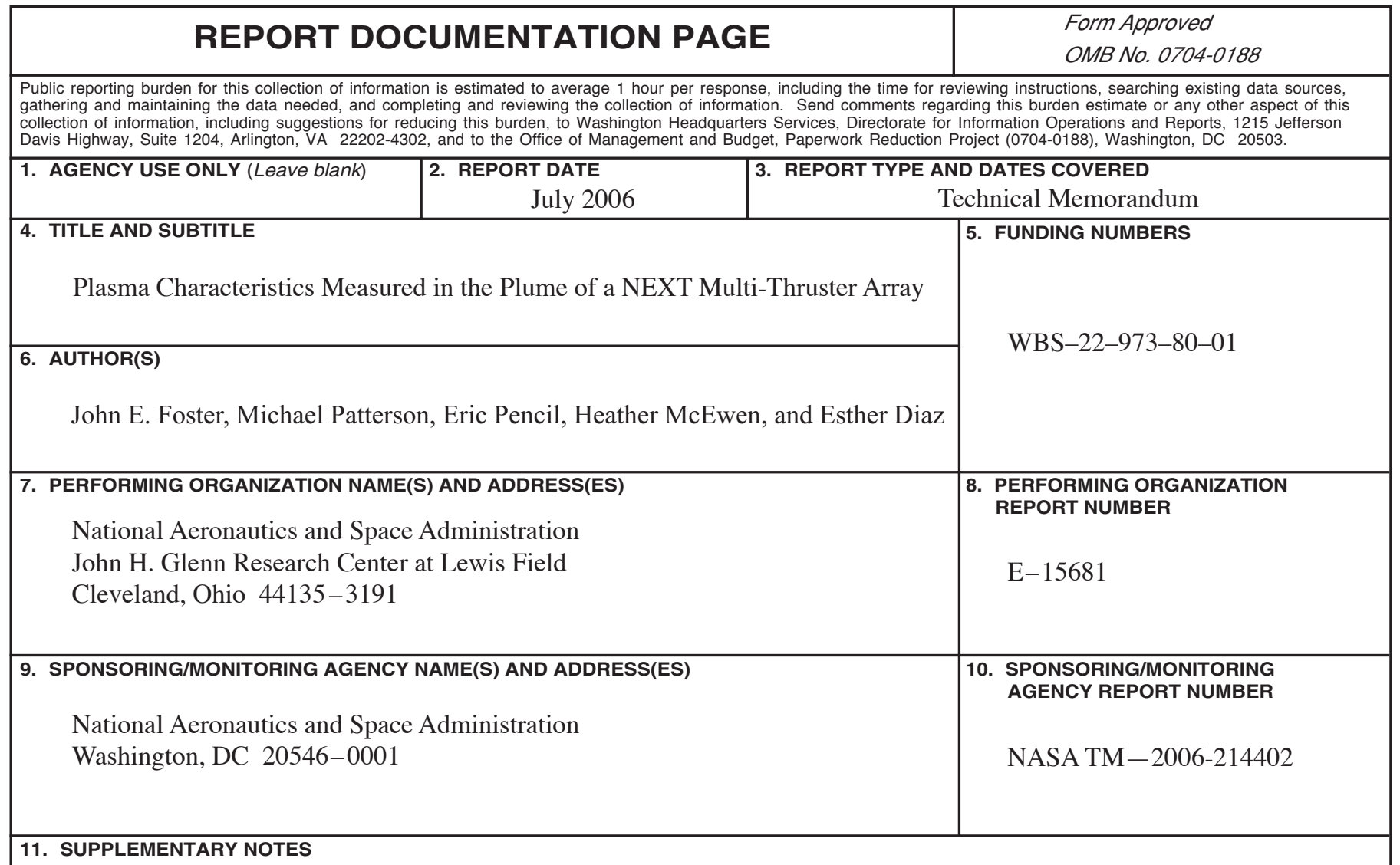

Prepared for the 42nd Joint Propulsion Conference and Exhibit cosponsored by AIAA, ASME, SAE, and ASEE, Sacramento, California, July 9-12, 2006. Responsible person, John E. Foster, organization code RPP, $216-433-6131$.

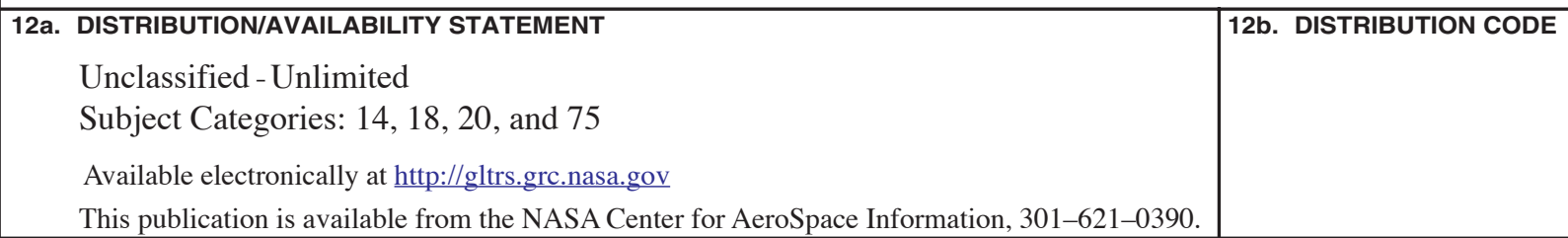

\section{ABSTRACT (Maximum 200 words)}

Plasma properties in the plume produced by a " $3+1$ " NEXT thruster array operating at full power were mapped using a series of planar Langmuir probes. The Langmuir probes were swept across the diameters of each thruster as well as the centerline of the array at multiple downstream axial locations to produce a plasma "map" of the plume produced by the array. Such maps yielded the spatial distribution of the plasma density, the electron temperature and the plasma potential in the near field of the array. This spatial information provides insight into local plasma particle flow. Flow direction is particularly important from both an array lifetime and spacecraft-plume plasma interaction standpoint. The variation in the plume plasma parameters tended to vary in a manner consistent with both plume shape and overlap of adjacent plumes.

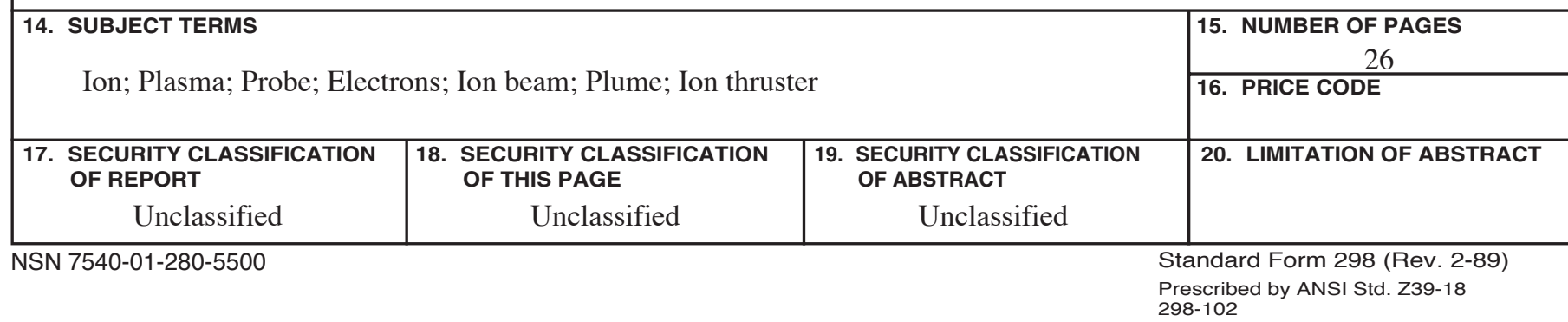



